\title{
ASSESSING LIFE-LONG LEARNING IN A FIRST-YEAR DESIGN AND COMMUNICATION COURSE
}

\author{
R.W. Brennan ${ }^{1}$, M. Eggermont ${ }^{1}$, W. Rosehart ${ }^{1}$, A.K. Deacon ${ }^{2}$, N. Larson ${ }^{2}$, and T.A. O'Neill ${ }^{2}$ \\ ${ }^{1}$ Schulich School of Engineering, University of Calgary \\ ${ }^{2}$ Department of Psychology, University of Calgary \\ Email: rbrennan@ucalgary.ca
}

\begin{abstract}
This paper reports on a pilot study of the assessment of CEAB (Canadian Engineering Accreditation Board) graduate attribute 3.1.12 "life-long learning" in a first year design course. We propose equating life-long learning with self-directed learning, and use the Self-Directed Learning Readiness Scale (SDLRS) developed by Guglielmino. The results of our survey show our first year students' readiness for selfdirected learning is very consistent with the adult average reported by Guglielmino and that the SDLRS instrument appears to be a good choice for the assessment of lifelong learning.
\end{abstract}

Keywords: First year engineering: accreditation: life-long learning

\section{INTRODUCTION}

In 2008, the CEAB (Canadian Engineering Accreditation Board) [4] updated their criteria and procedures to include outcomes-based assessment and continuous improvement [5]. The new model requires Canadian engineering schools to demonstrate that the graduates of their programs possess a set of twelve graduate attributes. Like the student outcomes defined in the ABET engineering criteria [1], the CEAB graduate attributes can be divided into a set of "hard" engineering skills and a second, equally important, set of "soft" professional skills.

Although most engineering faculty are relatively comfortable assessing "hard" engineering skills (e.g., competence in engineering fundamentals, problem analysis, etc.), they are typically less comfortable with the second set of "softer" professional skills. This is partially related to engineering faculty members' expertise residing primarily in engineering science and design, but also to the difficulties associated with the assessment of "process skills" such as communication and teamwork, and especially "awareness skills" such as impact of engineering on society and the environment, and life-long learning [20].
For this study, we focus on the assessment of the lifelong learning graduate attribute (graduate attribute 3.1.12 [5]), which arguably, has posed the greatest difficulty in terms of assessment tools since the introduction of the graduate attributes criteria. We propose using a similar approach to that used by Shuman et al. [20] to address life-long learning for ABET's 'Engineering Criteria 2000" [15]. They equate life-long learning with selfdirected learning readiness and identify two potential instruments for this purpose: Guglielmino's Self-Directed Learning Readiness Scale [13] and Oddi's Continuing Learning Inventory [18]. Given that the Self-Directed Learning Readiness Scale (SDLRS) has been in existence longer than the Continuing Learning Inventory and has been widely validated $[8,11,16]$, we chose the SDLRS for our study.

In this paper, we report on pilot study of student readiness for self-directed learning in a first-year design and communication course at the Schulich School of Engineering [3]. For this study, we had the students complete the SDLRS survey as part of a parallel study on student outcomes in the Fall 2013 term. Our plan is to use the results of the SDLRS as a baseline to assess life-long learning skills, and more specifically, to determine if courses designed to enhance students' readiness for selfdirected learning such as experiential learning courses $[10,14]$ achieve this purpose in our engineering programs.

We begin with an overview of the assessment of "lifelong learning". Next, we describe our research methods in Section 3, then present the results of our study with a group of first year design and communication students in Section 4. The paper concludes with a discussion of its appropriateness of the SDLRS as assessment tool for graduate attribute 3.1.12 "life-long learning". 


\section{ASSESSING LIFE-LONG LEARNING}

As noted by Litzinger et al. [16], life-long learning has been recognized as a critical engineering skill for many decades (e.g., $[2,7,17])$. In recent years, this importance has been highlighted by the inclusion of a life-long learning outcome in both the ABET engineering accreditation criteria within EC2000 [1, 15] and the CEAB graduate attributes criteria $[4,5]$.

ABET criterion 3(i) states that U.S. undergraduate engineering programs should prepare students to recognize the need for and have the ability to engage in life-long learning [1]. CEAB criterion 3.1.12 states that graduates of Canadian undergraduate engineering programs should have an ability to address their own educational needs in a changing world in ways sufficient to maintain their competency and allow them to contribute to the advancement of knowledge [5].

Life-long learning is multifaceted, and can be thought of in terms of both attributes (e.g., openness to learning opportunities) and skills (e.g., basic study skills) [6]. However, at its core, life-long learning involves taking responsibility for one's own learning. As a result, work in this area has recognized the tight link between life-long learning and readiness for self-directed learning. This can be seen when comparing Guglielmino's [13] definition of the self-directed learner and the ABET and CEAB definitions of life-long learning:

"A highly self-directed learner, based on the survey results, is one who exhibits initiative, independence, and persistence in learning; one who accepts responsibility for his or her own learning and views problems as challenges, not obstacles; one who is capable of self-discipline and has a high degree of curiosity; one who has a strong desire to learn or change and is self-confident; one who is able to use basic study skills, organize his or her time and set an appropriate pace for learning, and to develop a plan for completing work; one who enjoys learning and has a tendency to be goal-oriented." [13]

Despite wide-spread agreement on the importance of life-long learning, there is a lack of understanding within the engineering education community about the best means to develop and assess life-long learning skills within the curriculum. As early as the mid-1980's this challenge was tackled by the U.S. Panel on Continuing Education [18], who looked at types of activities associated with life-long learning skills development, and by Cervero et al. [16], who studied the ways in which practicing engineers engage in life-long learning.

Tools for assessing self-directed learning readiness were developed by Guglielmino [7] and Oddi [18], while research on the characteristics and models of self-directed learning was conducted by Candy [6] and Garrison [12].
More recently, work is being conducted on the impact of learning activities in undergraduate education on the development of life-long learning skills. For example, Litzinger et al. [16] use Guglielmino's Self-directed Learning Readiness Scale (SDLRS) [13] in a crosssectional study to determine if and how readiness for selfdirected learning varies across the years of undergraduate engineering programs and type of learning activity at Pennsylvania State University. Their results show that SDLRS scores are significantly correlated with year of study and GPA; however, neither year of study nor GPA were shown to be strong predictors of SDLRS scores. They also show that problem-based learning increases the average readiness for self-directed learning. A similar study was performed by Dynan et al. [10] with business students. They use the SDLRS to show that student readiness for self-directed learning increases when students are involved in learning activities that require self-directed learning practice (i.e., unstructured environments where students are afforded greater opportunities to shape their work).

In the next section, we describe the approach used in our study of first year engineering students' readiness for self-directed learning.

\section{DESIGN OF THE STUDY}

\subsection{First Year Design and Communication}

Both this study and our parallel study on predicting engineering student learning outcomes reported at this conference [9] were conducted in the Fall 2013 term in the Schulich School of Engineering first year common core course, Engineering 200 "Engineering Design and Communication". This course is intended to provide all Schulich School of Engineering students with an introduction to engineering principles, design, communications, leadership, and project management through a sequence of team-based design projects.

Presently, the course is offered each Fall term to approximately 715 first-year students, who are divided into 4 lecture cohorts of approximately 180 students and 24 laboratory cohorts of approximately 30 students. The laboratory cohorts are further divided into student teams of 4 students.

The first year student population at the Schulich School of Engineering is drawn predominantly from a high-school admission cohort. Given that the survey reported in this paper was conducted in the middle of the Fall term, the results are representative of a young adult population with limited exposure to post-secondary education. 


\subsection{The SDLRS Survey}

As noted previously, we chose Guglielmino's Selfdirected Learning Readiness Scale (SDLRS) [13] to assess graduate attribute 3.1.12 "life-long learning" [5]. This choice of instrument was made (1) for consistency with similar studies in the engineering and business education literature (e.g., [10], [14], [16], [20]), and (2) because of the instrument's established reliability and validity as a measure of readiness for self-directed learning [8].

For our survey, we use the "Learner Preference Assessment" instrument, developed in 1982. The Learner Preference Assessment instrument is provided with a distribution of scores for adult learners for whom the mean score is 214 and the standard deviation is 25.59 . Scores of 202-226 are considered to be "average"; scores of 227-251 are considered to be "above average"; scores of 252-290 are considered to be "high". The survey was conducted online in the middle of the Fall 2013 term using Survey Monkey [21], and students were encouraged to participate with an incentive of a $\$ 5$ gift cards (from a national coffee shop) was offered to each of the first 100 participants.

\subsection{Research Question}

In order to gain further insights into the assessment of graduate attribute 3.1.12 "life-long learning", we explored the following research question:

Is the Self-directed Learning Readiness Scale (SDLRS) a good predictor of engineering students' ability to engage in life-long learning?

Additionally, we were interested in gaining experience with the use of the SDLRS survey with a relatively large cohort of undergraduate students.

\section{RESULTS}

The results of the first year design and communication course survey are shown in Figure 1. Class enrolment in Fall 2013 was 692 students, resulting in a survey response rate of $28 \%$.

As can be seen in this figure, our first year students' readiness for self-directed learning is very consistent with the adult average reported by Guglielmino [13] (i.e., SDLRS of 214 with a standard deviation of 25.59). This is not surprising given that these students are predominantly fresh out of high school, and have had relatively limited exposure to learning activities that require self-directed learning practice.

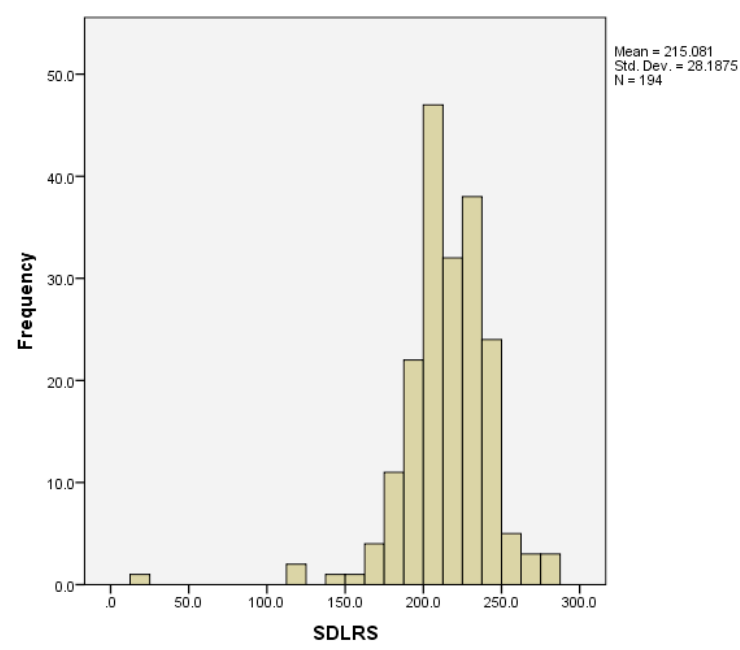

Fig. 1. SDLRS results - Engineering 200, Fall 2013.

\section{CONCLUSIONS}

Although the results of this study are very preliminary in nature, when placed in combination with the promising work on the impact of self-directed learning focused learning activities on student readiness for self-directed learning (e.g., [10], [14], [16], [20]), the SDLRS instrument appears to be a good choice for the assessment of life-long learning. As a predictor of life-long learning, there is strong support for the SDLRS's use in this context. However, as noted previously, life-long learning is multifaceted, and as such, should be assessed in the context of a group of attributes and skills that overlap with other desired student outcomes such as communication, investigation, and problem solving.

Our future work in this area will focus on determining if the learning activities embedded in our undergraduate programs are effectively building students' readiness for self-directed learning. Based on the research in this area, project-based learning activities such as those used in Engineering 200 appear to be a good starting point for this line of study. In Fall 2014, we plan to perform pre- and post-study of Engineering 200 using the SDLRS in order to determine if project-based learning activities positively impact student readiness for self-directed learning.

\section{Acknowledgements}

The authors wish to thank the Suncor Energy Foundation and the Schulich School of Engineering for their generous support of this research. As well, we would like to thank the students of Engineering 200 "Engineering Design and Communication" for their support and commitment to continuous improvement at the Schulich School of Engineering. 


\section{References}

[1] ABET, 2014-2015 Policies and Procedures Manual, 2014, Available as of 8 April 2014 from http://www.abet.org/accreditation-criteria-policiesdocuments/

[2] The American Society for Engineering Education Goals Committee, E.A. Walker, Chair, "Goals of Engineering Education: Final Report of the Goals Committee," Journal of Engineering Education, January 1968, pp. 367-446.

[3] R.W. Brennan, W.D. Rosehart, M. Eggermont, "First year design and communication: challenges and opportunities," in Proceedings of the 5th International CDIO Conference, (Singapore; 7-10 June 2009), 11 pp., 2009.

[4] Canadian Engineering Accreditation Board, 2014, Available as of 8 April 2014 from http://www.engineerscanada.ca/e/pr_accreditation.cfm

[5] Canadian Engineering Accreditation Board, Accreditation Criteria and Procedures, 2013, Available as of 8 April 2014 from http://www.engineerscanada.ca/sites/default/files/ w_Accreditation_Criteria_Procedures_2013.pdf

[6] P. Candy, Self-Direction for Lifelong Learning: A Comprehensive Guide to Theory and Practice. San Francisco, CA: Jossey-Bass, 1991.

[7] R.M. Cervero, J.D. Miller, and K.H. Dimmock, "The Formal and Informal Learning Activities of Practicing Engineers," Engineering Education, vol. 85, no. 11, pp. 112-116, 1986.

[8] J. Maltby, C. Lewis, and A. Hill, Commissioned Reviews of 250 Psychological Tests. Wales, U.K.: Edwin Mellen Press, 2000.

[9] A.K. Deacon, N. Larson, T.A. O’Neill, R.W. Brennan, M. Eggermont, and W. Rosehart, "The Self-Directed Learning Readiness Scale, conscientiousness, and the prediction of engineering student learning outcomes," in Proceedings of the 5th Canadian Engineering Education Association Conference, (Canmore, Alberta, 8-11 June), 2014.

[10] L. Dynan, T. Cate and, K. Rhee, "The impact of learning structure on students' readiness for self-directed learning", Journal of Education for Business, pp. 96-100, NovemberDecember 2008.
[11] L. Field, "An investigation into the structure, validity, and reliability of Guglielmino's self-directed learning readiness scale," Adult Education Quarterly, vol. 41, pp. 92-99, 1999.

[12] D.R. Garrison, "Self-directed learning: toward a comprehensive model," Adult Education Quarterly, vol. 48, pp. 18-33, 1997.

[13] L.M. Guglielmino, Development of the Self-Directed Learning Readiness Scale, Doctoral dissertation, University of Georgia, 1977.

[14] S. Jiusto and D. DiBiasio, "Experiential learning environments: do they prepare our students to be selfdirected, life-long learners?" Journal of Engineering Education, vol. 95, no. 3, pp. 195-204, 2006.

[15] L.R. Lattuca, P.T. Terenzini, J.F. Volkwein, Engineering Change: A Study of the Impact of EC2000. ABET Inc., 2006.

[16] T.A. Litzinger, J.C. Wise and S.H. Lee, "Self-directed learning readiness among engineering undergraduate students," Journal of Engineering Education, vol. 94, no. 2, pp. 215-221, 2005.

[17] National Academy of Engineering, The Engineer of 2020. Washington, D.C.: National Academy Press, 2004.

[18] L.F. Oddi, "Development and validation of an instrument to identify self-directed continuing learners," Adult Education Quarterly, vol. 36, pp. 97-107, 1986.

[19] Panel on Continuing Education, "Engineering Education and Practice in the United States - Continuing Education of Engineers," National Research Council Committee on the Education and Utilization of the Engineer, Washington, D.C. 1985.

[20] L.J. Shuman, M. Besterfield-Sacre and J. McGourty, "The ABET "Professional skills" - can they be taught? can they be assessed?," Journal of Engineering Education, vol. 94, no. 1, pp. 41-55, 2005.

[21] Survey Monkey, Online Survey Tool, 2014, Available as of 8 April 2014 from https://www.surveymonkey.com/ 